\title{
1. Equality, social justice and older people
}

\section{Rosie Harding}

In this chapter I explore the concepts of equality and social justice for older people in the context of arguments for and against the need for a new Convention on the Rights of Older Persons. I interrogate the effectiveness of different theoretical approaches to equality (equality of resources, equality of recognition, equality of power and equality of condition) that could underpin arguments about the need for new international human rights protection for older people. In evaluating each of these "equality"-based approaches, I demonstrate why each falls short as a justification for a new convention. In response to the limitations of an equality approach, I argue that we need to turn towards an understanding of social justice for older people, and suggest that a capabilities approach, building on the work of Amartya Sen and Martha Nussbaum, offers the most persuasive conceptual basis for a new convention. I argue that the capabilities approach, which requires not only the discursive and rhetorical enunciation of rights but also their substantive realization, is the most effective way to understand both equality and social justice for older people.

I develop my argument in three sections. In the first section, I provide a brief introduction to the social and legal arguments for a Convention on the Rights of Older Persons, demonstrating the central place that equality and social justice aims hold within the movement for older people's rights. In the second section, I explore different conceptualizations of equality and measure each of these against the arguments in favour of a new convention. I turn, in the third section, to explore the utility of the "capabilities approach" developed by Sen $(1985 ; 1995 ; 1999 ; 2010)$ and Nussbaum $(1999 ; 2007 ; 2013)$ as a rationale for older people's rights. I argue for the need to shift from equality arguments towards social justice, building on the capabilities approach to make the case for a new convention on older people's rights. 


\section{TOWARDS AN INTERNATIONAL CONVENTION ON OLDER PERSONS' RIGHTS}

Social, legal and political movements towards a new international Convention on the Rights of Older Persons have emerged since the beginning of the twenty-first century (Rodriguez-Pinzon and Martin, 2003), with momentum gathering apace since around 2010. Reasons for the emergence and escalation in calls for a new international legal instrument may include increased awareness of the human rights issues facing older people, following a range of "soft law" international agreements; the success of the UN Convention on the Rights of Persons with Disabilities (CRPD); and the emergence of a range of national and international Non-Governmental Organizations (NGOs) focused on older people's rights (Doron and Apter, 2010).

The earliest United Nations (UN) activities on the topic of ageing can be traced back as far as the World Assembly on Ageing in Vienna in 1982, which led to the Vienna International Plan of Action on Aging (United Nations, 1983). This initial plan on tackling the challenges of ageing in the international context grew from the work of the Economic and Social Council on issues to do with age and ageing (United Nations, 1982). These historical foundations go some way towards explaining why older people's rights have (largely, though not exclusively, in the past) been more often considered economic, social and cultural rights (ESCR), rather than substantive civil and political rights. This then generates "the perception that these 'rights' are only aims or goals" (Rodriguez-Pinzon and Martin, 2003: 921).

The Second World Assembly on Ageing, which took place in Madrid in April 2002, led to the replacement Madrid International Plan of Action on Ageing (United Nations, 2002). This new international plan shifted the focus from humanitarian aspects of ageing in developed countries, to responding to the challenges posed by ageing in the developing world (Sidorenko and Walker, 2004). The Madrid plan significantly expanded the scope of recommendations and priority areas for action. As Sidorenko and Walker (2004) argue, this change in emphasis and expansion of the scope of the plan 'indicates the replacement of 'compassionate ageism', which regards older people as a 'deserving' group, with the acceptance of their rights to equal treatment and self-determination" (Sidorenko and Walker, 2004: 153). The explicit acknowledgement of older people's human rights in the Madrid plan arguably paved the way towards the 2009 Expert Group Meeting on the "Rights of Older Persons" in Bonn, organized by the Division for Social Policy and Development of the UN 
Department of Economic and Social Affairs (UN DESA, 2009). The Expert Group meeting agreed that both normative gaps and implementation gaps had been generated by the complex and piecemeal coverage of age within existing (soft and hard) international law. Possibilities for closing these gaps and strengthening rights protections for older people that were proposed by the expert group included the appointment of a special rapporteur on older people's rights, and a new international convention, which "could create new principles that would empower older persons, provide older persons with greater visibility and recognition, both nationally and internationally and provide the foundational basis for advocacy, public awareness and education on the rights of older persons" (UN DESA, 2009: 18). Whilst neither of these substantive recommendations from the expert group were immediately acted upon, they undoubtedly provided the impetus for escalating work on older people's rights in the last decade, and specifically in the establishment of the Open-Ended Working Group on older persons' human rights (Doron, 2015).

Several substantive gaps in international protections of older people's human rights were identified in the Report of the UN High Commissioner for Human Rights to the Economic and Social Council (UNHCHR, 2012). These gaps included: ageism and age-based discrimination; the challenge of ensuring older people are afforded their rights to legal capacity and equal recognition under the law; rights associated with long-term care, including rights to liberty and security of the person, privacy, freedom of movement, freedom of expression, and freedom from torture and inhuman or degrading treatment; and rights to an adequate standard of living and the highest attainable standard of physical and mental health. The increased risk of violence and abuse that older people face, particularly those reliant on others for care and support, and the challenges of access to justice when older people experience abuse were also identified as problems, as were the challenges that older age generates in access to work, food security and housing. Rights to social protection and social security were highlighted as generating particular issues for older people. Finally, protection gaps were identified in relation to the right to access an adequate standard of healthcare, including access to appropriate palliative and end-of-life care. More recently, these concerns were reiterated by the Independent Expert on the enjoyment of all human rights by older persons, Rosa KornfeldMatte, in her report to the UN Human Rights Council (Kornfeld-Matte, 2016).

The sheer breadth of these gaps in the international human rights protection regime as it relates to older people provides an important 
baseline for thinking about the arguments for and against a new Convention on the Rights of Older People. Doron and Apter (2010) suggest that the two key arguments for a new convention are simply that these gaps exist, and that the creation of a convention would operate as "an effective legal tool to promote and advance the social position of older persons in the future" (Doron and Apter, 2010: 588). Arguably, the discursive shift towards thinking of older people as holders of substantive rights that has been catalyzed by the social movements and legal discussions around the creation of a new convention would also help to shift understandings of ageing, and go some way towards challenging the current gap in human rights protection. These are strong arguments, and yet there are also a range of convincing arguments against the need for a specific convention for older people. One of the main arguments against is that older people's rights are fully covered by the universal guarantees in the existing international human rights framework. Instead of focusing energies on the legal and political process that would lead to a new convention, the energy of social movement activists might be better expended making arguments for better substantive protection and implementation of the existing international human rights protections. Relatedly, there are arguments to suggest that previous "specific" conventions, notably the Convention on the Elimination of Discrimination against Women (CEDAW) and the Convention on the Rights of the Child (CRC), have not actually generated significant international shifts in the human rights protection of women or children. Indeed, some commentators argue that these specific rights instruments have made the situation worse, rather than better, even indirectly legitimizing some human rights infringements (Doron and Apter, 2010).

The aim of this chapter is to take one step back from these political and legal arguments around whether a convention on the rights of older persons is appropriate, desirable or necessary, in order to explore what the conceptual basis for such a convention would be. In the simplest of terms, we might understand the need for human rights protections for a group of people (older people) as a means to addressing their different treatment, as compared to the norm. So, if we understand older people as the non-normative group, the normative group we would contrast them with would be people who are younger, or of middle age. ${ }^{1}$ Addressing systematic disadvantage experienced by the non-normative group means addressing the multiple inequalities and/or social injustices that they experience in their everyday lives. In this chapter, I seek to argue that a social justice approach, such as that provided by the "capabilities approach" (Sen, 1985; 1995; 1999; 2010; Nussbaum, 1999; 2007; 2013) offers a more robust justification for a new convention than an equalities 
approach, even though exploring the gaps in human rights protection for older persons exposes a range of pressing inequalities across multiple domains.

\section{THE POTENTIAL AND LIMITS OF EQUALITY AS A RATIONALE FOR OLDER PERSONS' RIGHTS}

Despite being a fundamental value of many national constitutions, and a core normative principle with ancient roots (such as the Aristotelian edict that likes should be treated alike), equality remains an awkward concept. It is difficult to find agreement on a definition of what equality means in any detailed and functional sense, beyond the very simple core of like-alike-ness. Notwithstanding that most would agree that at the very least, all human beings have "equal worth and importance, and are therefore equally worthy of concern and respect" (Baker et al., 2004: 23), equality has been described as a myth, because it has "no independent meaning or definition and can be understood in conflicting and incompatible ways" (Fineman, 2004: 25-6).

The heart of the problem that equality presents is that the object of equality, sometimes referred to as equality's "what", has been given wildly different content by different theorists. As Amartya Sen has noted, theoretical engagements with the concept of equality look to what equality is attempting to achieve, and "every normative theory of social arrangement that has at all stood the test of time seems to demand equality of something" (Sen, 1995: 12). Various different conceptions of what the "something" is that is necessary for equality have been propounded: examples include equality of resources (for example, Dworkin, 2002), equality of recognition (for example, Fraser, 1997), equality of condition (Baker et al., 2004) and equality of power (for example, Cooper, 2004). In the context of arguments for a new convention on the rights of older people, as I will demonstrate, these different approaches to equality's object can each help to support arguments for addressing some of the gaps in international human rights protections, but none can offer comprehensive solutions to the identified normative and implementation gaps.

\section{Resources}

Equal distribution of resources has always been a central idea within theoretical approaches to equality. It is most commonly used to refer to equal distribution of financial resources such as income and wealth 
(Baker et al., 2004). Theoretical engagements with how to ensure the equal distribution of resources tend to take private property (or "things" which can be divided up between individuals) as the starting point of discussion. Perhaps the most well-known proponent of "resources" as the best way to conceptualize equality's "what" is Ronald Dworkin (1977; 2002), whose equal auction example provides a persuasive argument in favour of resource distribution from a social starting point of zero.

Aside from the impossibility of restarting the distribution of resources from a starting point of everyone having nothing, perhaps the most problematic aspect of Dworkin's (2002) conceptualization of equality of resources is his apparent belief in the ability of "the market" to provide a fair distribution of resources. The limitations of this belief become plainly evident in the increasing gap between rich and poor in late capitalist economies. Thinking back to the gaps identified by the UN High Commissioner for Human Rights (UNHCHR, 2012), inequality of resources is clearly a significant factor in issues relating to access to an adequate standard of living for older people, food security, access to appropriate housing, and access to quality palliative and end-of-life care. Additional redistribution of financial and practical resources to those in need should, in theory, resolve inequalities in access to these social goods. The problem, however, lies in the inadequacy of redistributive welfare systems in late capitalist societies.

Consider, as an example, the problem of access to quality, affordable care services to support the activities of daily living for older persons living in the community. ${ }^{2}$ Gerontological research has clearly identified a preference by older people to "age in place" (Callahan, 1992; Vasunilashorn et al., 2011). Most people would prefer to have care services they require provided to them in their own homes than move into residential or nursing care environments. Yet access to this kind of care and support requires the means to pay for it. State-funded care is available in England, through means testing, to those with the highest level of need and the lowest level of resources. Yet the current financial position of social care funding means that not only will there be an anticipated funding gap of $£ 5.8$ billion by 2020 in England (Local Government Association, 2017), but UK government spending on social care is estimated to fall to less than 1 per cent of GDP by 2020 (Nuffield Trust et al., 2016). The funding gap in social care that has arisen as a result of year-on-year cuts to local authority budgets since 2010 (totalling some 30 per cent of local government budgets) has meant an overall reduction in the numbers of people accessing publicly funded social care by 26 per cent. This reduction in state-provided care does not remove the care needs that were previously being supported. Instead, given the relational 
context that care is provided in and through (Harding, 2017), the lack of governmental will to provide resources for care pushes the cost of providing that care onto the person who requires care, and their families and carers. It can, for example, force family carers to give up paid employment to provide care, which then in turn generates future resource problems if people of working age are unable to earn sufficient income to save for their own older age (Harding, 2017). This privatization of care also has an uneven effect, exacerbating gendered inequalities, because women are still more likely than men to provide care to family members; and increasing the stigma of disability and illness in older age, because older people do not want to be a "burden" on their families.

A second limitation of an equality of resources approach to protecting the human rights of older persons is that if older persons' rights are primarily expressed in terms of socioeconomic rights, rather than civil and political rights, then the potential for relatively weak enforcement mechanisms and wide-ranging limitations or derogations may increase. Prior to the global economic crisis, there had been a move away from considering "civil and political rights" and "economic, social and cultural rights" as distinct groupings of rights, and recognizing the interrelationships between them (UNHCHR, 2008). Yet the response of the Committee on Economic, Social and Cultural Rights (CESCR) to the international economic crisis suggests a move back towards understanding socioeconomic rights as substantively different from civil and political rights, and allowing states to resile from them in times of economic emergency. In a letter to states, the CESCR effectively offered a new accommodations model for the times of economic crisis, disrupting the development of the doctrine of non-retrogression, and making it easier for states to roll back socioeconomic rights (Warwick, 2016). This, in turn, retrenches the "traditional message that only socio-economic rights have economic consequences (and thus that economic emergencies are only relevant to those rights)" (Warwick, 2016: 261).

Reliance on a resource equality perspective as the foundation for a new convention on the rights of older persons may not, therefore, provide enough of a rationale to remove the currently existing implementation gaps in relation to, for example, standard of living, access to social security, housing or food that older persons experience. Further, grounding older persons' rights in a resource equality context would need to address the fundamental challenges posed by the late capitalist (neoliberal) economic system, which perpetuates socioeconomic inequality through exploitation, marginalization and deprivation (Fraser, 1997). Redistribution of resources in our current economic climate cannot happen as a one-off measure, but rather must continue in an ongoing 
fashion in order to even begin to address the realities of unequal distribution of resources. Ongoing redistribution through means-tested political approaches does not, however, do anything to challenge the structures which generate or support resource inequality, nor is it capable of removing economic inequalities (Fraser, 1997: 25).

Turning back to the example of social care services, the market in these services is essentially dysfunctional. The provision of care services requires resources. The limited resources that are allocated to the system, alongside the market ideology that underpins it, mean that it is unable to respond to need. The private enterprise nature of care service providers requires that companies and agencies providing care are profitable (if they are not, then they fold, leading to failures of care and neglect). In order to be profitable, social care service providers must pay low wages, rely on zero hours contracts and other forms of precarious labour, and offer poor working conditions to care staff (Hayes, 2017), which then perpetuates cycles of resource inequality into the future. Governmental interventions that seek to increase wages for the lowest paid (such as the planned increases to the UK national minimum wage in the coming years) can only work where they are backed up with appropriate investment. In the context of care, ongoing cuts to local authority budgets simply mean that fewer people will have access to state support to pay for care, which means that a greater proportion of care needs will have to be provided for privately. That private funding will either operate, as it does currently, to subsidize state provision if it is paid for by self-funding recipients, or will (again) force family members to choose between their own paid employment and paying for care, or providing that care themselves (Harding, 2017). Either way, the costs of caring are reprivatized, and continue the cycle of redistribution into the future. Distributive justice is, and will continue to be, a fundamental aspect of inequality, and one of the major problems associated with ageing. Yet it is clear that equality of resources is insufficient as a conceptual rationale for a new Convention on the Rights of Older Persons, because addressing maldistribution alone will not address the systemic problems associated with the undervaluing of care and support in society (Harding et al., 2017).

\section{Recognition}

One of the great debates in equality theory has been between those who argue that the correct object of equality is resources, and those who see the target of equality as more appropriately addressing misrecognition of particular groups. Of all the different approaches to "equality of what" that have been put forward, equality of recognition seems, at first glance, 
to be the "what" of equality that is most relevant to challenging ageism or other forms of discrimination against marginalized groups. Arguments for equality of recognition may offer additional justifications for a Convention on the Rights of Older Persons (Doron, 2015). Whereas the redistribution of tangible resources may well enable older persons to access a higher standard of living, through access to better health, food, housing and care by being facilitated to pay more for such goods, viewing equality through the lens of recognition may offer different solutions to other gaps in contemporary human rights protections for older people. Ageism and age discrimination, which build on stereotypes of older people as incapacitated, disabled, in ill health and past their social usefulness, would, for example, be effectively challenged through equality of recognition for older persons. Recognizing that chronological age is not a determinant of capacity or ability to work or to contribute to society in other ways, would arguably catalyze significant gains for older people.

Nancy Fraser (1997) distinguished cultural or symbolic injustice from socioeconomic inequalities, arguing that cultural domination, nonrecognition and disrespect create distinct forms of inequality that recognition would address. It is important to note that this distinction between redistribution and recognition is a theoretical one, which does not presume that in practice the two are entirely separate problems as "economic injustice and cultural injustice are usually interimbricated so as to reinforce each other dialectically" (Fraser, 1997: 15). Fraser uses the operation of heterosexism and homophobia to devalue lesbian and gay sexuality as an example of inequality that is rooted in an "unjust cultural-valuational structure" (1997: 18), arguing that if lesbian and gay sexuality were re-valued as equally respectable to heterosexuality, then the problem of lesbian/gay inequality would be solved. Although Fraser prefaces her theoretical argument with a disclaimer that in reality cultural and socioeconomic inequalities are linked and supportive of each other, she uses the example of lesbian/gay sexuality as one where any economic inequalities would also be resolved through the recognition and re-valuation of non-heterosexual sexuality. This example, and Butler's (1998) response to it, can be extended to consider whether equality of recognition would provide an effective conceptual basis for a new Convention on the Rights of Older Persons.

In her critique of Fraser's location of lesbian and gay sexuality exclusively within the cultural sphere, Butler (1998) highlighted the ways in which heteronormativity works to support the economic system, through the sexual division of labour and the "reproduction of the normative family" (Butler, 1998: 40). Thus, she argues, the labelling of 
homophobia and heterosexism as "merely cultural" removes and confounds the relationship between the regulation of sexuality and modes of production in a capitalist economic system. Crucially, however, heteronormativity does not only produce effects on sexuality, and the heteronormative ordering of society also works to generate particular patterns of stereotypes about ageing. Historical patterns of employment, alongside the gendered allocation of childcare and household labour, are also embedded in heteronormativity.

Consider, for example, the ways in which women's working patterns alongside differential compulsory retirement ages have historically worked to create socioeconomic disadvantage for older women. In the UK, despite women's life expectancy being consistently longer than men's (ONS, 2016), historically, state retirement ages for women were set at 60 , whereas men were unable to retire until the age of 65 . This difference, combined with the greater likelihood of women either giving up paid employment entirely for a period of time to care for children, or working part time, has made it more difficult for women to save for retirement, to build up sufficient national insurance contributions to be entitled to a full state pension, or to access employers' pensions. The persistent gender pay gap, even in full-time employment, compounds this difference (Costa Dias et al., 2016). Whilst changes have been made in recent years, including the removal of mandatory retirement ages and an increase in the age at which women are entitled to receive a state pension in the UK, this has not necessarily been either intended to address the historical disadvantages experienced by women, nor has it had that effect. Rather, increases in the state pension age have been intended to reduce the pension bill and implemented as part of a range of "austerity" cuts, and have generated significant financial problems for many older women. Various policies have been introduced at different points as a mechanism for introducing post hoc amelioration for these kinds of income inequalities in older age, including through redistribution of wealth through state benefits like Pension Credit. Yet finding a long-term solution to income disparity between older men and women requires a combination of both equality of resources and substantive gender equality, with changes to patterns of domestic labour, childcare, and closing the gender pay gap in both employment and retirement. Whilst some progress has been made in some of these areas, despite the formal prohibition of sex discrimination in employment over 40 years ago, ${ }^{3}$ more than two-thirds of pensioners living in poverty in the UK are women, and the income of older women is, on average, 15 per cent less than that of men (Turner, 2016). It is clear that equality of recognition and equality of resources are substantially 
interlinked. Neither approach, therefore, can offer a complete solution to the disadvantages experienced by older persons.

\section{Power, Condition}

In response to the limitations of the resources versus recognition dynamic in equality studies, some commentators have suggested more allencompassing approaches to equality's object. Davina Cooper (2000; 2004) argues for a conception of "equality of what", that moves away from the difficulties of a dichotomous emphasis on resources and recognition, towards equality as nobody having "an inherent right to impact more on their social and physical environment than anyone else" (Cooper, 2004: 77-8). Unlike conceptions of equality of resources or recognition, which are rooted in group-based identifications, equality of power takes the "moral equality of living humans" (Cooper, 2004: 68) as the subject of equality. Unlike the conception of equality of power as restricted to political power (see for example, Dworkin, 2002: 184-210), this version of equality of power extends to the social world as well as to the exercise of power within the operation of the state.

In Dworkin's (2002) conception of equality of power, he considered power solely in terms of political power, situated in ideas of democracy and the distribution of political power within a community, both horizontally (between individuals) and vertically (between individuals and state officials) (Dworkin, 2002: 190-91). Dworkin (2002) also saw the distinction between influence and impact, where impact refers to the difference an individual can make on their own, and influence refers to the ways in which an individual can induce others to believe or choose in the same way as essential to his or her conception of equality of power (Dworkin, 2002: 191). Dworkin argues in favour of influence over impact, but then argues that equal influence is not an achievable possibility in a democracy, and that it should simply be positioned as an ideal, within a system of representative democracy, where majoritarian views will take precedence over true equality of power within a political system (Dworkin, 2002: 194-200). An important difference, then, is between the ways in which equality of power is conceived as a purely political ideal (Dworkin, 2002) and where it is thought of as also encompassing social, cultural and economic aspects of life (Cooper, 2004).

In contrast, Cooper's $(2000 ; 2004)$ approach to equality of power argues that all people should have the same capacity to impact their environment, whilst recognizing that interests, desires and goals will vary. This version of equality of power takes the individual as the "who" of equality, but it does so without relying on the problematic assumptions 
of liberal "sameness" models of the individual, through an explicit recognition of the ways in which nobody actually belongs to a single "group" and the problems of intersectionality (Cooper, 2000: 257). The most fundamental way in which Cooper's (2004) conception of equality of power differs from that espoused by Dworkin (2002) is that rather than taking a conventional definition of power as a "right" which is exercized, Cooper uses Foucault's (1980) conception of power as net-like, where power is concerned with the production of effects.

Here again, however, the focus on equality of "what" leads to a difficulty within theorizing equality - that in order for individuals to have equal power, or equal capacity to produce effects, there must already be some form of parity between individuals in relation to (at least) resources and recognition. In theoretical terms, taking power as the object of equality is difficult to fault, but when considering the exercise of power, or rather, individuals' capacities to produce effects through their actions, inequalities of resources, opportunity and recognition seem to complicate the picture. Where, for example, an individual is disadvantaged by a lack of resources, they may not physically be able to get themselves to the place where their voice may be heard, or where they can exercize power to produce effects. Similarly, those disadvantaged through a lack of knowledge or ability to express themselves, perhaps caused by the effects of inequality of opportunity on their education, may find that they are disadvantaged in that they are unsure of where to turn to impact their environment. If some groups are inherently undervalued or "misrecognized", as older people often are, their voices are less likely to be heard, or their impact less likely to be felt, because their concerns may not be understandable to those around them - especially if their concerns are far removed from the wishes and desires of the "majority". In essence, it is necessary to dismantle social, cultural, religious and structural barriers, such as the regulation of the family, and differential access to healthcare, education and employment, before it can begin to be possible for all individuals to have the same power to impact their environment.

Another all-encompassing theory of the object of equality, proposed by Baker et al. (2004), is equality of condition. This has similar aims to equality of power, in that it seeks a solution that is not concentrated on a singular area of inequality (for example, resource, opportunity, recognition) but rather focuses on the practical dimensions of life where change is needed to achieve equality in a substantive, material sense. The distinctive element of their "equality of condition" approach is that it explicitly includes the affective domain, through equality of love, care and solidarity, as well as the more usual objects of equality (like resources, opportunity, recognition). They argue that all humans have 
"both a need and a capacity for intimacy, attachment and caring relationships" (Baker et al., 2004: 37). Consequently, they argue that "In caring for others, we act to meet their needs in a way that involves an attitude of concern or even love ... . Love involves acting for those we love, not just feeling for them. Solidarity involves active support for others, not just passive empathy." (Baker et al., 2004: 37)

This aspect of equality's "what" is often neglected in economically focused approaches to equality, yet is vital to thinking about equality for older people. It highlights the ways in which certain relationships of love, care and solidarity are prioritized over others. Caretaking (whether for children or for older or disabled people) is often argued to be a neglected or invisible but still fundamental and essential component of society, as well as one which operates to keep women subordinated to men (see for example, Fineman, 2004). Importantly, not all relationships of love, care and solidarity are given equal value or respect in society. When caretaking and dependency relationships are considered, for example, it is the relationship between parents and young children which most obviously springs to mind, rather than issues of caring for the older persons or adults with disabilities. Whether within institutionalized care settings or within the context of "the family", these caring relationships are arguably of the utmost importance, as these forms of dependency and caretaking are less normative and yet can be at least as longstanding, if not more so, as the caring/depending relationship between parent and child. When an older person (or someone affected by a debilitating illness) becomes unable to care for themselves, the responsibility for care tends to fall on family members - in particular on women, which brings us back, again, to the problems generated by inequalities of both resources and recognition which would also need to be addressed in order to make any practical or substantive move towards equality of condition for older people.

\section{Equality Theory and the Case for a New Convention}

In this section I have given a brief overview of some of the main theories of the object of equality. I have discussed resources, recognition, power and condition as possible focuses of equality, and highlighted the limitations of each of these in relation to addressing systemic problems of injustice faced by older people. The key problem, it seems, with equality-based arguments, is that putting in place practical measures to address inequality in one domain can either generate new or additional inequalities in other domains, or can be dependent on further shifts in other domains relating to both the subject and object of equality. So, for 
example, addressing income inequality in older age requires not only redistributive welfare-based models, but also substantive changes in working patterns across the life course. Yet such changes would impact on caring labour and choices in the affective domain. It seems that whilst it is vital that we address inequalities of condition, and we introduce law and policy at national and international levels that seek to address them, equality as a conceptual justification for a new convention on the rights of older persons falls short because of the challenge of identifying what the object of equality should be. For older persons, we can see that equality of power, of resources, of recognition, of love, care and solidarity and of condition are all important. Any convention on older persons' rights will inevitably have egalitarian aims, and when it is introduced its success will be measured on the basis of certain spaces of equality (Sen, 1995).

Looking back to the "gaps" identified above, we can see that issues of ageism, age discrimination, equal recognition before the law and the right to enjoy legal capacity, access to appropriate care and to work might all be addressed by a convention based on understandings of equality of recognition for older people. Mechanisms to address resource inequality in older age might ensure an adequate standard of living, of health, of food and nutrition, of housing, and quality care services. Alongside these, equality of condition might provide justifications for the need for quality palliative and end-of-life care, access to work and leisure pursuits in older age. Equality of power might offer solutions to problems associated with deprivation of liberty, invasions of privacy, protection from violence and abuse, or freedoms of movement and expression. These different dimensions of equality each speak to different parts of the injustices faced by older people. To argue for a convention on the basis of inequalities experienced by older people would, therefore, require the engagement of all of these complex theoretical justifications for equality. Unfortunately, these nuanced understandings of equality are always in danger of being erased in political and social movement discourse. Equality arguments often fall back to their simplest version, based on the Aristotelian idea of "like should be treated alike", which can make it difficult to argue effectively for extra support or resources for particular individuals or marginalized groups. Whilst it is essential, therefore, that inequality is appropriately attended to in discourse around the need for a new convention, it may be that a move away from equality discourse in the direction of a broader concept of social justice could be more effective as a baseline justification for increased human rights protections. 


\section{CAPABILITIES AND OLDER PEOPLE: AN ALTERNATIVE SOCIAL JUSTICE ARGUMENT FOR AN OLDER PERSON'S CONVENTION?}

As the above discussion has demonstrated, equality arguments require a (more or less) specific object. The capabilities approach, as developed by Sen (1985; 1995; 1999; 2010) and Nussbaum (1999; 2007; 2013), in contrast, offers a different conceptual rationale for social, legal and political action towards justice. In this section I offer an argument that the capabilities approach provides a more coherent and persuasive justification for the need for a new supranational convention on the rights of older persons than equality theory.

Sen (1995) recognized the limitations of theories of "equality of what" and proposed a different model of understanding the conceptual justification for social justice through the capabilities approach. In Sen's words, "the capability approach points to the need to examine freedom to achieve in general and capabilities to function in particular" (Sen, 1995: 129). In this approach, rather than focusing on (in)equality as the locus of regulatory or governmental action, Sen shifts attention to ask what people need in order to have the freedom to be and to do what they choose or value. A second dimension to Sen's capabilities approach is the prominence that he gives to public reasoning in identifying and debating capabilities and functionings. He argues that the capabilities approach requires public discussion, because this "can lead to a better understanding of the role, reach and significance of particular functionings and their combinations" (Sen, 2010: 242). This dual focus (looking at what is required to enable people to live their lives in ways which respect and support their values and choices about what they prefer to do and to be, and giving space for public discussion of capabilities and functionings) generates opportunities to think differently about both national and international regulatory frameworks and human rights instruments.

One of the main impacts of Sen's work on capabilities has been the establishment of the Human Development Index, to provide an alternative method of measuring prosperity at a national level, rather than the neoliberal, capitalist-focused measure of Gross Domestic Product (GDP) per capita that is more often used. Sen (1999) argues convincingly that GDP per capita is both ineffective and misleading as a measure of the quality of life for all in a political state or area. This is because it cannot demonstrate how GDP is distributed across society (it is an average figure), leading to countries with vast inequalities scoring higher than they otherwise would (or should). The Human Development Reports, 
which are produced by the UN Development Programme with the aim of improving human well-being, regularly draw attention to the particular difficulties and challenges faced by older people. For example, the focus of the 2014 Human Development Report (UNDP, 2014) was "reducing vulnerabilities and building resilience", and included multiple references to the ways in which older people are structurally disadvantaged, or made more vulnerable by patterns of labour, and regulatory and economic choices. Sen's work on capabilities is, therefore, already shaping the international response to the challenges of supporting and respecting older people.

The second major theorist in the capabilities approach has been Martha Nussbaum. Unlike Sen, whose focus is on economic aspects of social justice through capabilities, Nussbaum's approach is founded in national and international constitutional law, including human rights law. In offering her version of the capabilities approach, Nussbaum $(1999,2013)$ has generated a list of "central capabilities" which she considers to be essential to "a dignified and minimally flourishing life" (2013: 32). Some of these capabilities are uncontroversial and well protected in existing international human rights documents. For example, "life", Nussbaum's first central capability, is protected through the "right to life" provisions in any number of national and international rights documents. ${ }^{4}$ The simple fact that "life" is already protected in such instruments does not, however, necessarily mean that all lives are as fully protected as they could or should be. Too often, the lives of older persons can be considered less important or less worthy of investment in, for example, health and social care, than the lives of younger people. Consider the example of the Quality Adjusted Life Years (QALY) measure used by the UK's National Institute for Health and Care Excellence (NICE). This tool is used to measure the cost effectiveness of possible treatments on the basis of the number of life years they add, adjusted by quality. The methodology, which is used to inform decisions about which treatments should be authorized to be given to NHS patients (Stevens et al., 2012), has been accused of ageism because it places a greater QALY value on outcomes for younger people than on older people (Harris and Regmi, 2012). Discrimination appears because the QALY includes a measurement of the number of life years that are added by a treatment, and an appraisal of their quality (with "healthy" years being more valuable and valued that "disabled" years), in combination with the cost of treatment to create the value which is used for deliberative purposes. So, for example, a treatment that cost $£ 500000$ which would provide normal life 
expectancy without disability for a 20-year-old would cost $£ 9000$ per year; a 45-year-old £14200 per year; and a 70-year-old $£ 33000$ per year. $^{5}$

Nussbaum's articulation of life as a central capability includes "being able to live to the end of a human life of normal length; not dying prematurely" (Nussbaum, 2013: 33). Yet this raises a number of further questions about how we estimate the length of a "normal" human life, given the wide disparities in life expectancy between and across different geographical and socioeconomic spaces. Longevity varies from continent to continent, country to country and individual to individual. Reasons why person A might live longer than person B include complex interplays of genetics, social and cultural contexts and choices, geographical location, as well as religious and political factors. The creation of a new convention on the rights of older persons would not change the inherent variability of life expectancy. It would, however, in the debates and discussions towards a new convention, offer a space for public reason, in the manner proposed by Sen (2010). This public discussion would provide space for deliberation of the justice dimension of the right to life as it applies to older persons. In doing so, it might facilitate robust public, political debate about the appropriate levels of resources required to safeguard life for older persons, and expose potentially or actually ageist methodologies, such as the QALY.

Closely related to life are Nussbaum's proposed central capabilities of bodily health and bodily integrity. Again, whilst these capabilities already find generic protection in existing legal instruments, older persons' interests require a different set of considerations from those of younger persons. For example, older persons may find that their bodily health is less resilient to poor nourishment, lack of heat or inadequate shelter than younger persons. Older people may also be more likely to find themselves in situations where they are dependent on others for care and support, and bodily integrity may be challenged or threatened through difficulties with securing high-quality, person-centred care that supports them in realizing their capabilities. If care assistants only visit at specific times during the day, this may, for example, limit the choices that older people have; or if older people are subjected to abuse and/or violence by those they depend on for care, this will inevitably limit their functionings. The central capabilities of bodily health and bodily integrity are therefore extremely important to older people in ways which may not be fully supported by current international human rights protections.

Nussbaum's fourth central capability highlights the importance of the senses, imagination and thought. Again, whilst freedom of conscience and expression are generally well protected in existing human rights law, 
the specific dimensions of these for older people are rarely considered. Public debate about the place of these capabilities might facilitate discussion of how access to religious services or rituals may be limited if an older person has restrictions on movement, or impaired mobility as a result of poor health or care needs. It may also, through the individual (rather than group) focus of the capabilities approach, draw attention to the ways that responsibilities for supporting older people in being and doing as they choose to do in these areas might fall unevenly onto family members (particularly women), rather than through public support. Public discussion of how to secure these capabilities for older people may help to generate persuasive arguments for a new convention by enabling the articulation of the normative and implementation gaps that currently exist in the rights of older persons not only to express and engage their religious and cultural preferences, but also to access the arts of their choosing, or to enjoy other entertainment like play. ${ }^{6}$

Nussbaum lists several other central capabilities, but there is not the space in this chapter to engage in depth with them all. ${ }^{7}$ Importantly, the work of discussing the capabilities that are most crucial to older people would be a vital element of preparatory discussions for a new convention on older persons' rights, and in the future interpretation by national and international bodies of the rights included in any such convention. Arguing for a new convention on the basis of the capabilities approach will not solve the dilemmas about where to draw the line on the redistribution of resources. Nor will it solve the dilemmas posed by equality theory about which domain of (in)equality requires the most pressing attention. The capabilities approach does, however, in both Sen's (1992; 1999; 2010) economically focused version and Nussbaum's (1999; 2007; 2013) list of central capabilities offer a discourse within which to ground activism and arguments towards a new Convention on the Rights of Older Persons. By shifting the focus of discourse away from considering how older people are disadvantaged, or especially vulnerable, ${ }^{8}$ a capabilities approach offers the starting point of considering what older people need in order to choose the "beings and doings" they value.

\section{CONCLUDING REMARKS}

The aim of this chapter has been to explore alternative conceptual rationales that could underpin activism and argument towards a new convention on the rights of older persons, if we were to shift our focus from the inequalities experienced by older people towards a capabilities 
approach. My aim has been to highlight some of the ways that public discourse around the rights of older people may be limited by a conceptual and rhetorical focus on (in)equality. I have offered the groundwork for an argument that the capabilities approach has the potential to offer a more coherent and persuasive conceptual basis for a new convention than arguments based on equality theory.

I have not, in this chapter, offered an argument for a new convention that builds from the capabilities approach. Indeed, the work in developing the arguments that could help in the movement towards a new convention is part of the ongoing project of challenging ageism and supporting the rights of older people. As activism, social movements and legal debate move us further towards the social and political conditions necessary to begin the work of constructing a convention on the rights of older persons, my argument is that a social justice focus, drawing on the capabilities approach, provides us with a set of persuasive discursive, rhetorical and legal tools to make the case for a new convention. I have, therefore, offered an argument that the capabilities approach can provide the necessary conceptual space for articulating why a new convention is required to address older persons' rights. I have demonstrated that it also provides both a necessary justification and conceptual basis for the need for public engagement, debate and discourse about older persons' rights.

\section{NOTES}

1. It would be easier to express this differential in terms of persons above or below a specific chronological age (for example, 60), but the use of chronological age in this way paradoxically contributes to ageism and age discrimination. If, for example, we say everyone over the age of 60 is 'older' we include many people who are of chronological ages greater than 60 , but who do not experience infringements of their human rights on that basis, but simultaneously exclude many others who are chronologically younger than 60 years old, but for whom ageing has already had a great impact on their rights. Chronological age is therefore only ever a proxy, which is modified and mediated by a range of intersectional axes of privilege and oppression (including for example, gender, ethnicity, disability, sexuality, religious beliefs, education level, socioeconomic resources, geographical location and other variables).

2. The examples provided here are from England, but the move away from social welfare towards private provision of care services is by no means limited to the English context.

3. Sex Discrimination Act 1975; Equal Pay Act 1970.

4. Some examples would include: the Universal Declaration of Human Rights, Article 3; the European Convention on Human Rights, Article 2; and the International Covenant on Civil and Political Rights, Article 6.

5. This calculation is based upon the figures used by Stevens et al. (2012). In that article, Stevens et al. argue that there is no inherent ageism within the QALY, using a treatment cost of $£ 450000$, and demonstrating that there would be no difference between the different exemplar age groups. There is not the space here to fully deconstruct their methodology - 
suffice to say the mathematical basis of the QALY is, in fact, inherently ageist (Harris, 2005), and ableist.

6. Play is another of Nussbaum's (2013) central capabilities. For an interesting discussion of the normative gap in the right to leisure in old age, see Karev and Doron (2017).

7. These include emotions, practical reason, affiliation both in relationships and in the sense of dignity; control over one's environment in both political and material terms; and the capability to live "with concern for and in relation to animals, plants and the world of nature" (p. 34).

8. For an argument about the potential of vulnerability theory in the context of older persons' rights, see Chapter 2 by Titti Mattsson.

\section{REFERENCES}

Baker, J., Lynch, K., Cantillon, S. and Walsh, J. (2004). Equality: From Theory to Action. Basingstoke: Palgrave Macmillan.

Butler, J. (1998). Merely cultural. New Left Review, I/227: 33-44.

Callahan, J.J. (1992). Aging in Place. Amityville, NY: Baywood Publishing Company.

Cooper, D. (2000). "And you can't find me nowhere": Relocating identity and structure within equality jurisprudence. Journal of Law and Society, 27(2): 249-72.

Cooper, D. (2004). Challenging Diversity: Rethinking Equality and the Value of Difference. Cambridge: Cambridge University Press.

Costa Dias, M., Elming, W. and Joyce, R. (2016). The Gender Wage Gap. London: Institute for Fiscal Studies. Accessed on 20 December 2016 at https://www.ifs.org.uk/uploads/publications/bns/bn186.pdf.

Doron, I. (2015). Ithaka: On the journey to a new international human rights convention for the rights of older persons, in R. Ruebner, T. Do and A. Taylor (eds), International and Comparative Law on the Rights of Older Persons, pp. 18-34. Lake Mary, FL: Vandeplas Publishing.

Doron, I. and Apter, I. (2010). The debate around the need for an international convention on the rights of older persons. The Gerontologist, 50(5): 586-93.

Dworkin, R. (1977). Taking Rights Seriously. Cambridge, MA: Harvard University Press.

Dworkin, R. (2002). Sovereign Virtue: The Theory and Practice of Equality. Cambridge, MA: Harvard University Press.

Fineman, M.A. (2004). The Autonomy Myth: A Theory of Dependency. New York, NY: The New Press.

Foucault, M. (1980). Power/Knowledge: Selected Interviews and other Writings, Colin Gordon (ed.). New York, NY: Pantheon.

Fraser, N. (1997). Justice Interruptus: Critical Reflections of the "Postsocialist" Condition. New York, NY: Routledge.

Harding, R. (2017). Duties to Care: Dementia, Relationality and Law. Cambridge: Cambridge University Press.

Harding, R., Fletcher, R. and Beasley, C. (eds) (2017). ReValuing Care in Theory, Law and Policy: Cycles and Connections. Abingdon: Routledge.

Harris, J. (2005). It's not NICE to discriminate. Journal of Medical Ethics, 31: 373-5. 
Harris, J. and Regmi, S. (2012). Ageism and equality. Journal of Medical Ethics, 38(5): 263-6.

Hayes, L.J.B. (2017). Stories of Care: Gender and Class at Work. London: Palgrave.

Karev, I. and Doron, I. (2017). The human right to leisure in old age: Reinforcement of the rights of an aging population. Journal of Aging \& Social Policy, 29(3): 276-95.

Kornfeld-Matte, R. (2016). Report of the Independent Expert on the enjoyment of human rights by older persons A/HRC/33/44. Accessed on 26 January 2017 at http://ap.ohchr.org/documents/alldocs.aspx?doc_id=26860.

Local Government Association (2017). Adult Social Care Funding: State of the Nation 2017. London: Local Government Association. Accessed on 27 February 2018 at https://www.local.gov.uk/sites/default/files/documents/1.69\% 20Adult $\% 20$ social $\% 20$ care $\% 20$ funding- $\% 202017 \% 20$ state $\% 20$ of $\% 20$ the $\% 20$ nation_07_WEB.pdf.

Nuffield Trust, Health Foundation and King's Fund (2016). The Autumn Statement: Joint Statement on Health and Social Care. Accessed on 2 December 2016 at https://www.kingsfund.org.uk/sites/files/kf/field/field_publication_file/ Autumn_Statement_Kings_Fund_Nov_2016_3.pdf.

Nussbaum, M.C. (1999). Women and equality: The capabilities approach. International Labour Review, 138(3): 227-45.

Nussbaum, M.C. (2007). Frontiers of Justice: Disability, Nationality, Species Membership. Cambridge, MA: Harvard University Press.

Nussbaum, M.C. (2013). Creating Capabilities: The Human Development Approach. Cambridge, MA: Harvard University Press.

Office of National Statistics (2016). National Life Tables, UK: 2013-2015. Accessed on 15 December 2016 at https://www.ons.gov.uk/peoplepopulation andcommunity/birthsdeathsandmarriages/lifeexpectancies/bulletins/nationallife tablesunitedkingdom/20132015.

Rodriguez-Pinzon, D and Martin, C. (2003). The international human rights status of elderly persons. American University International Law Review, 18(4): 915-1008.

Sen, A. (1985). Commodities and Capabilities. Oxford: Oxford University Press.

Sen, A. (1995). Inequality Reexamined. Oxford: Oxford University Press.

Sen, A. (1999). Development as Freedom. Oxford: Oxford University Press.

Sen, A. (2010). The Idea of Justice. London: Penguin Books.

Sidorenko, A. and Walker, A. (2004). The Madrid International Plan of Action on Ageing: From conception to implementation. Ageing \& Society, 24(2): 147-65.

Stevens, A., Doyle, N., Littlejohns, P. and Docherty, M. (2012). National Institute for Health and Clinical Excellence appraisal and ageism. Journal of Medical Ethics, 38(5): 258-62.

Turner, C. (2016). The gender pay gap means that more women will be in poverty later in life - but there is something the government can do. The Independent, 26 August. Accessed on 20 December 2016 at http://www. independent.co.uk/voices/gender-pay-gap-women-will-be-in-poverty-late-in-lifebut-there-is-something-the-government-can-do-a7210931.html. 
United Nations (1982). Report of the World Assembly on Aging. New York, NY: United Nations. Accessed on 27 February 2018 at https://www.un.org/ development/desa/ageing/resources/vienna-international-plan-of-action.html.

United Nations (1983). Vienna International Plan of Action on Aging. New York, NY: United Nations. Accessed on 27 February 2018 at http://www.un.org/es/ globalissues/ageing/docs/vipaa.pdf.

United Nations (2002). Madrid International Plan of Action on Ageing. New York, NY: United Nations. Accessed on 27 February 2018 at https://www.un. org/development/desa/ageing/madrid-plan-of-action-and-its-implementation.html.

UN DESA (2009). Report of the ExpertGroup Meeting "Rights of Older Persons". Accessed on 27 February 2018 at http://www.un.org/esa/socdev/ ageing/documents/egm/bonn09/report.pdf.

UN DP (2014). Sustaining Human Progress: Reducing vulnerabilities and building resilience. Human Development Report 2014. New York, NY: UNDP. Accessed on 26 January 2017 at http://hdr.undp.org/en/content/humandevelopment-report-2014.

UNHCHR (2008). Frequently Asked Questions on Economic and Social Rights: Factsheet No. 33. New York, NY: Office of the UN HCHR. Accessed on 26 January 2017 at http://www.ohchr.org/EN/Issues/ESCR/Pages/ESCRIndex. aspx.

UNHCHR (2012). Report of the United Nations High Commissioner for Human Rights (GE12-42071, E/2012/51). Accessed on 26 January 2017 at http:// www.un.org/ga/search/view_doc.asp?symbol=E/2012/51.

Vasunilashorn, S., Steinman, B.A., Liebig, P.S. and Pynoos, J. (2011). Aging in place: Evolution of a research topic whose time has come. Journal of Aging Research, 2012, doi:10.1155/2012/120952.

Warwick, B.T.C. (2016). Socio-economic rights during economic crises: A changed approach to non-regression. International \& Comparative Law Quarterly, 65(1): 249-65. 